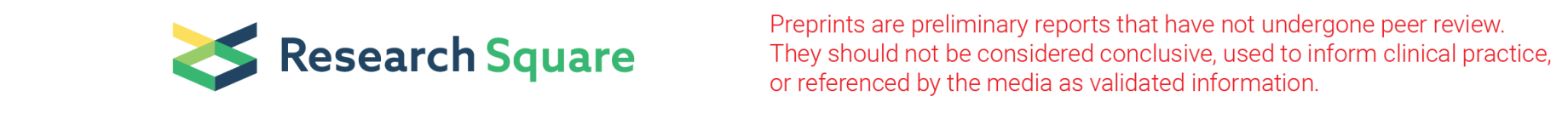

\title{
A Broadband Dual Circularly Polarized Compact Printed Monopole Antenna
}

Rohit Kumar Saini ( $\nabla$ rohitccsu@gmail.com )

NIMS University https://orcid.org/0000-0002-1562-3281

\section{Research Article}

Keywords: Dual circular polarization, Two port antenna, Polarization diversity, Printed monopole antenna

Posted Date: April 13th, 2021

DOI: https://doi.org/10.21203/rs.3.rs-414741/v1

License: (1) This work is licensed under a Creative Commons Attribution 4.0 International License. Read Full License 


\section{Abstract}

A microstrip line - fed broadband dual circular polarized, two port printed monopole antenna is presented. The antenna consists of a ground plane with arrow shaped stub at the corner and a pair of inverted L-shaped feed lines. The $3 \mathrm{~dB}$ axial ratio bandwidth of the antenna is about $58 \%(1.7 \mathrm{GHz}-3.1 \mathrm{GHz})$ in which the return loss and isolation are better than $10 \mathrm{~dB}$ and $12 \mathrm{~dB}$ respectively. A parametric study of proposed antenna's geometric parameters is given for understanding of the antenna performance. The realize gain, reflection coefficient (S 11 ) and transmission coefficient (S 21 ) are higher than 1, 10 and $12 \mathrm{~dB}$ respectively within the entire axial ratio bandwidth (ARBW).

\section{Full Text}

This preprint is available for download as a PDF.

\section{Tables}

TABLE I

3-dB AR BANDWIDTH, VOLUME, ELECTRICAL SIZE, TYPE and $\mathrm{f}_{\mathrm{C}}$ OF SOME EXISTING DUAL CP ANTENNAS

\begin{tabular}{|c|c|c|c|c|c|c|c|c|}
\hline Ref. & [20] & {$[21]$} & [22] & [23] & [24] & [25] & [26] & Proposed \\
\hline AR BW(\%) & 4.7 & 12.85 & 16 & 7.25 & 20.8 & 59.65 & 80.7 & 58 \\
\hline Volume $\left(\mathrm{mm}^{3}\right)$ & - & $60 \times 60$ & $76 \times 76 \times 0.726$ & $252 \times 252 \times 1.6$ & $83 \times 83 \times 1$ & $60 \times 60 \times 1.6$ & $32 \times 32 \times 1$ & $60 \times 60 \times 0.8$ \\
\hline $\begin{array}{c}\text { Electrical } \\
\text { Size }(L \times W)\end{array}$ & - & $\begin{array}{c}0.69 \times 0.69 \\
\lambda_{g}^{2}\end{array}$ & $\begin{array}{c}1.08 \times 1.08 \\
\lambda_{g}^{2}\end{array}$ & $\begin{array}{c}1.187 \times 1.187 \\
\lambda^{2}{ }_{g}\end{array}$ & $\begin{array}{c}0.748 \times 0.748 \\
\lambda_{\mathrm{g}}^{2}\end{array}$ & $\begin{array}{c}0.657 \times 0.657 \\
\lambda_{\mathrm{g}}^{2}\end{array}$ & $\begin{array}{c}0.245 \times 0.245 \\
\lambda^{2}{ }_{g}\end{array}$ & $\begin{array}{c}0.558 \times 0.558 \\
\lambda^{2}{ }_{g}\end{array}$ \\
\hline $\begin{array}{l}\text { Type of } \\
\text { Antenna }\end{array}$ & $\begin{array}{l}\text { Annular } \\
\text { Slot } \\
\text { Antenna }\end{array}$ & $\begin{array}{c}\text { CPW Slot } \\
\text { antenna }\end{array}$ & $\begin{array}{c}\text { Dual } \\
\text { Substrate } \\
\text { with back } \\
\text { Cavity }\end{array}$ & $\begin{array}{c}\text { Dual } \\
\text { Substrate }\end{array}$ & $\begin{array}{c}\text { Microstrip } \\
\text { Slot } \\
\text { antenna }\end{array}$ & $\begin{array}{l}\text { CPW Slot } \\
\text { antenna }\end{array}$ & $\begin{array}{c}\text { Monopole } \\
\text { Antenna }\end{array}$ & $\begin{array}{l}\text { Monopole } \\
\text { Antenna }\end{array}$ \\
\hline $\begin{array}{c}\mathrm{f}_{\mathrm{C}}(\mathrm{GHz}) \text { of } \\
\text { ARBW }\end{array}$ & 2.46 & 2.45 & 3.7 & 0.9 & 2.6 & 2.85 & 6.27 & 2.4 \\
\hline
\end{tabular}

\section{Figures}

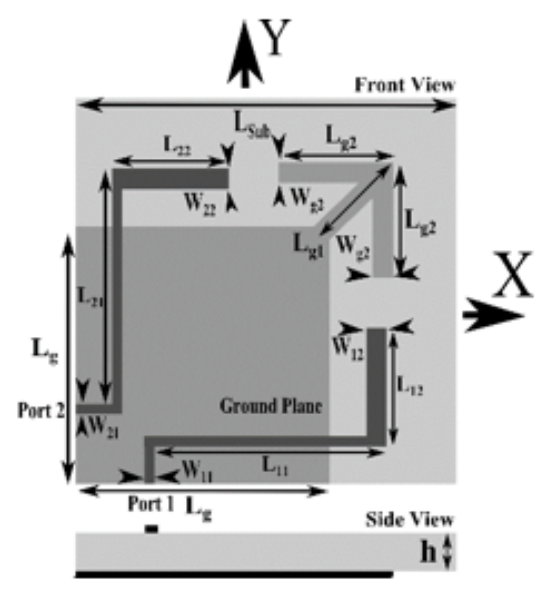

Figure 1

Configuration of the proposed two port planar monopole antenna. (LSub =60, L11 \& L21 =38.2, L12 \& L22 =16.8, W11 \& $\mathrm{W} 21=1.6, \mathrm{~W} 12 \& \mathrm{~W} 22=3.2, \mathrm{Lg}=40, \mathrm{Lg} 1=9.62, \mathrm{Lg} 2=18, \mathrm{Wg} 2=3.2$, and $\mathrm{h}=0.8)$ (Unit: millimeters). 


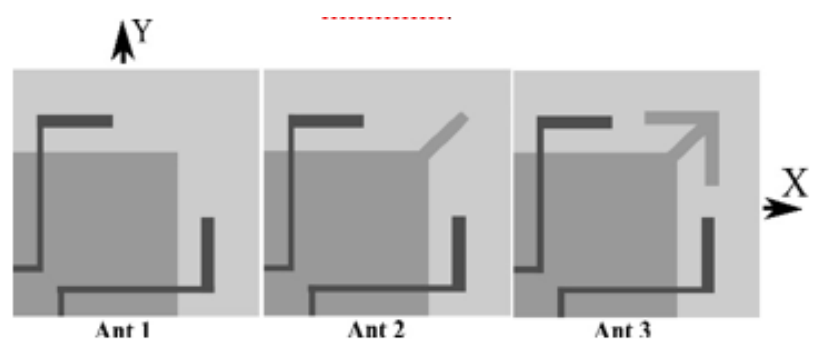

Figure 2

Steps of improvement of the proposed antenna.

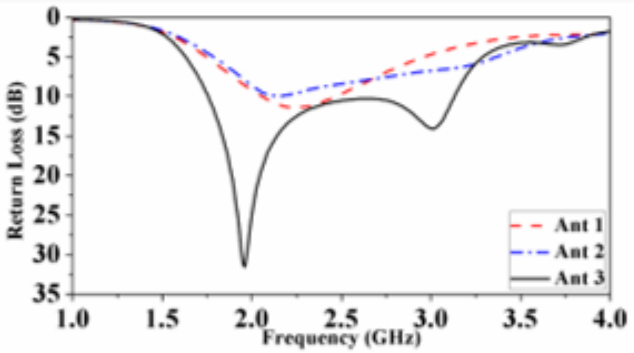

(a)

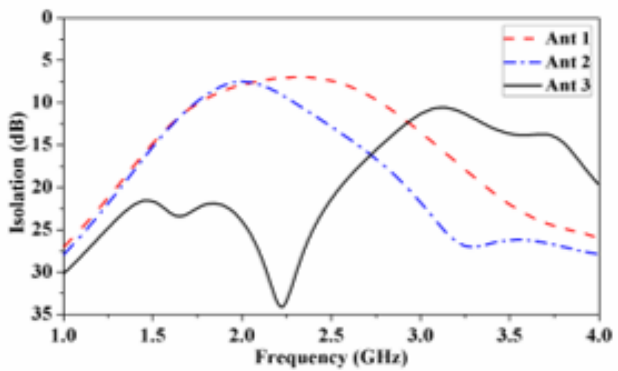

(b)

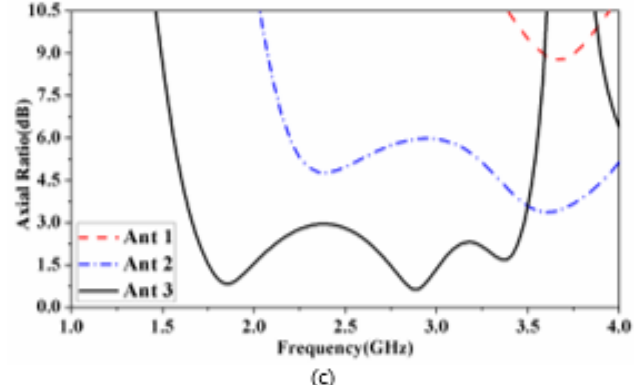

Figure 3

Simulated (a) $|S 11|,(b)|S 21|$ and (c) axial ratio of Ant 1-3. 


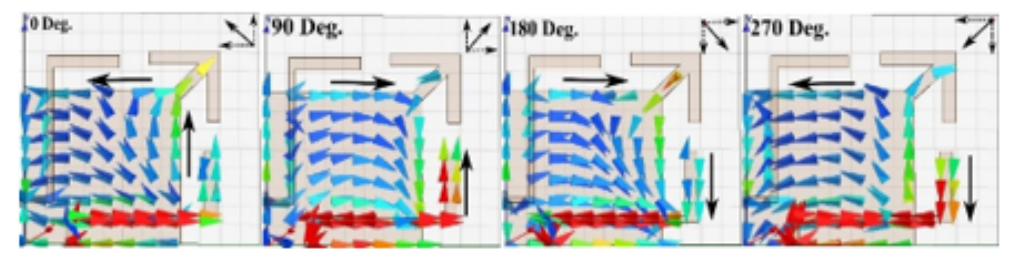

(a)

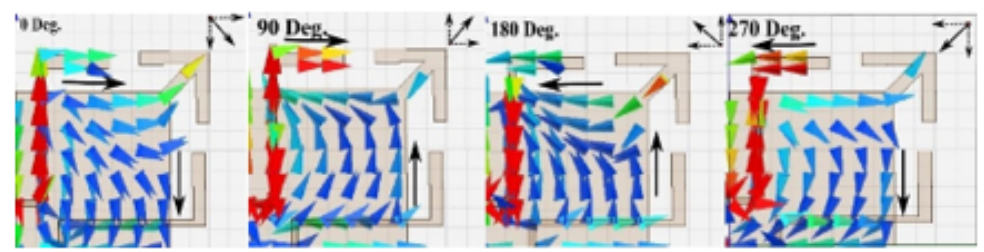

(b)

Figure 4

Surface current distributions of proposed antenna at 2.4GHz when the signal is applied: (a) Port 1, and (b) Port 2.

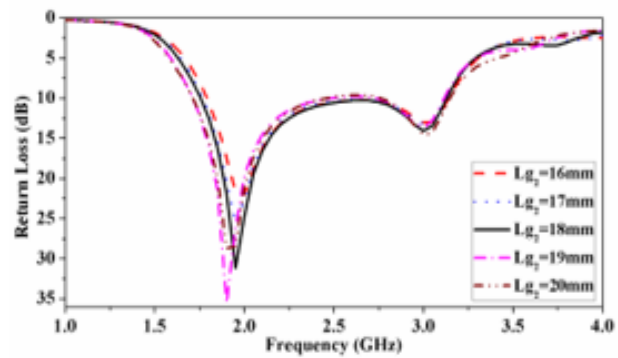

(a)

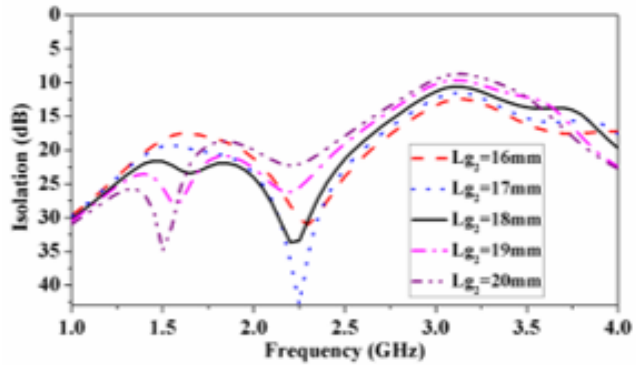

(b)

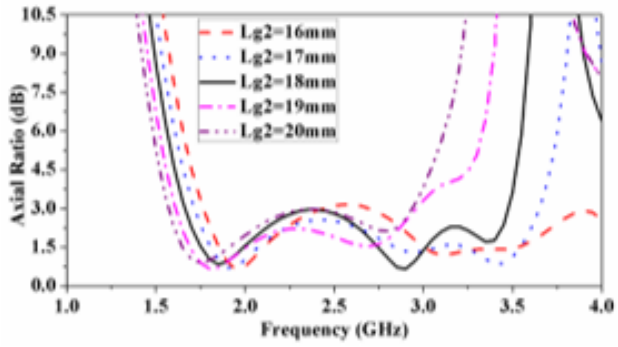

(c)

Figure 5

Effect of Lg2 on antenna characteristics (a) $|S 11|$, (b) |S21| and (c) axial ratio (axial ratio in $+Z$ direction). 


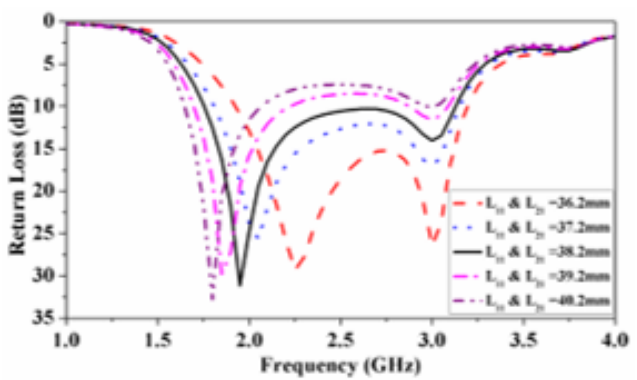

(a)

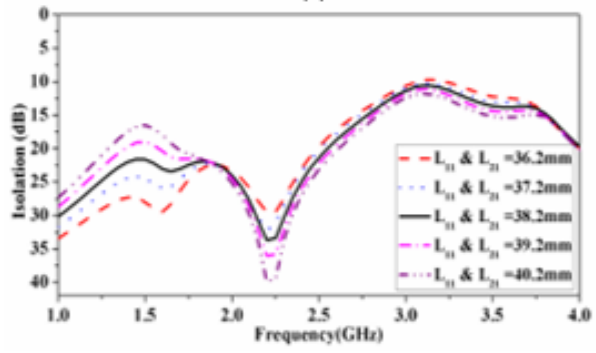

(b)



(c)

\section{Figure 6}

Effect of parameter L11 and L21 on antenna characteristics (a) $|S 11|$, (b) $|S 21|$ and (c) axial ratio (axial ratio in $+Z$ direction).

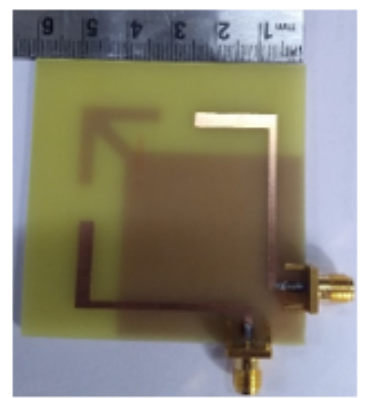

\section{Figure 7}

Photograph of the fabricated antenna. 


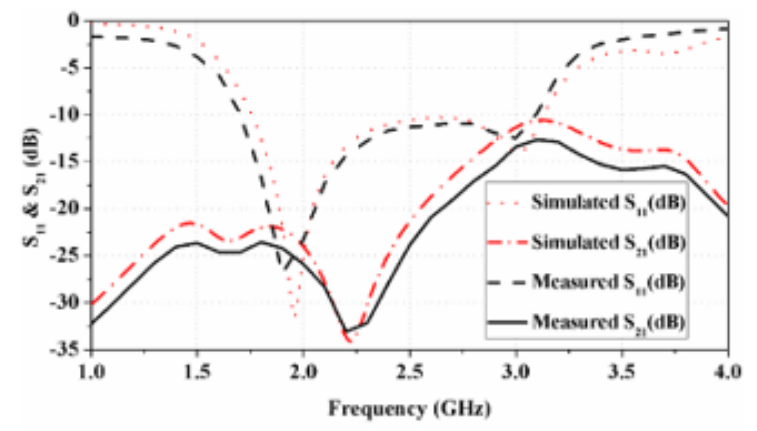

Figure 8

Measured and simulated return loss and isolation for the proposed antenna.

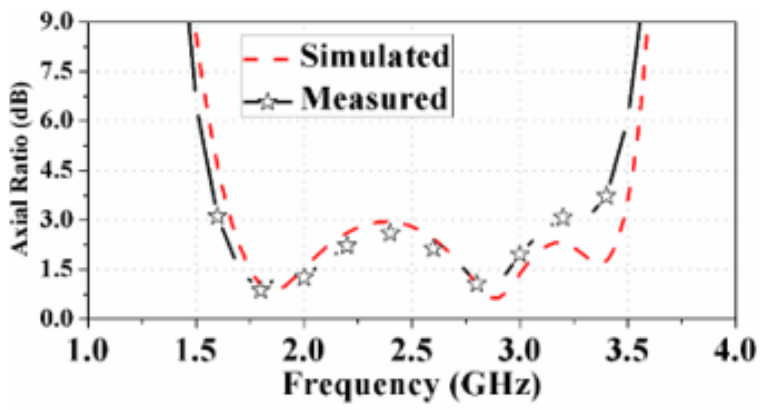

Figure 9

Measured and simulated axial ratio curves of the proposed antenna.

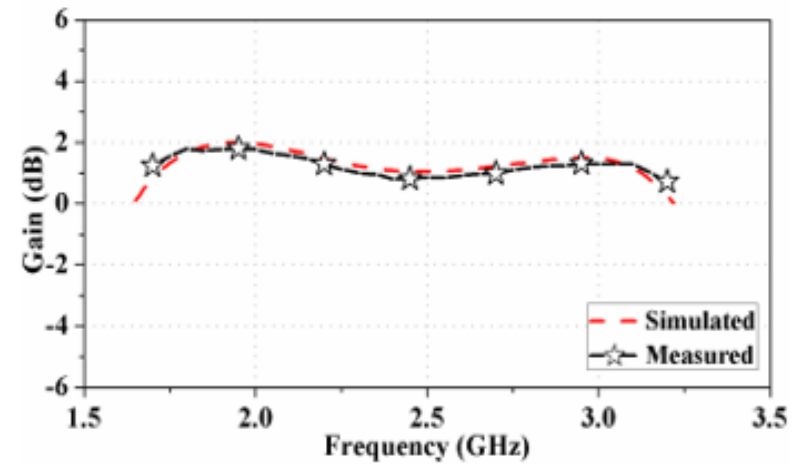

Figure 10

Measured and simulated gain of the proposed antenna. 

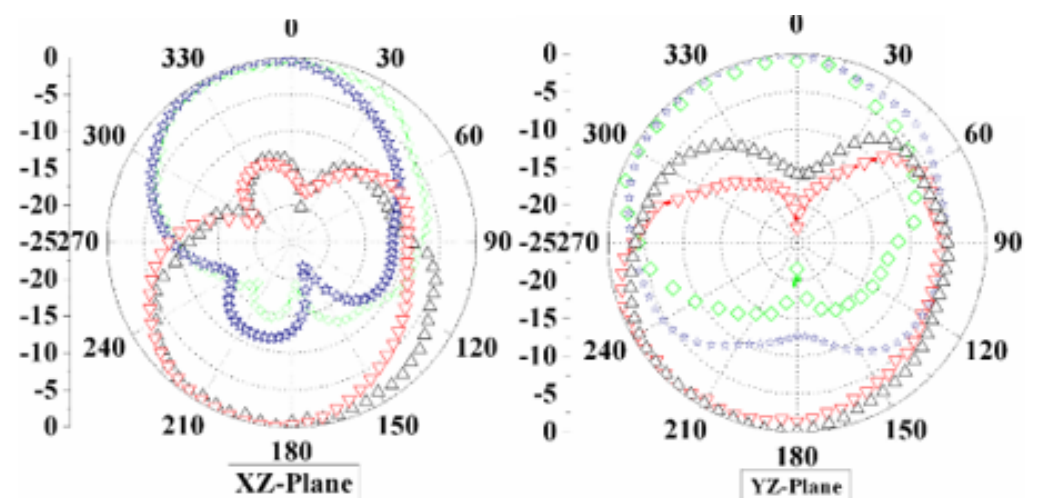

(a)
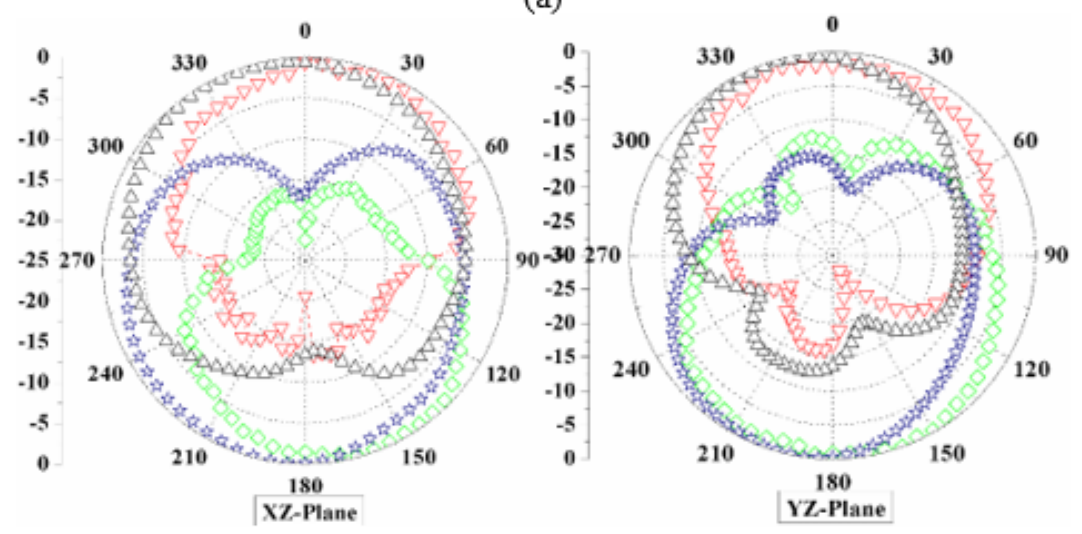

(b)

$\checkmark \checkmark$ Measured LHCP $-\checkmark-$ Measured RHCP $\cdots$ Simulated LHCP $\cdots-$ Simulated RHCP

\section{Figure 11}

Measured and simulated radiation patterns at $2.4 \mathrm{GHz}$ of the proposed antenna. Excitation in (a) port 1 and (b) port 2. 